\title{
Communication with Customers in Relationship Marketing. Comparative Study for Companies from Belgium and Romania.
}

\author{
Prof PhD Nicolae Al. Pop ${ }^{1}$, PhD cand. Raluca Nastase Anysz ${ }^{2}$, PhD cand. Andrada Baba ${ }^{3}$
}

123 The Bucharest University of Economic Studies, Council for Doctoral Studies, Bucharest, Romania

\begin{abstract}
.
Communication is the basis of human interaction and a success factor of the human species. Communication is more complex and differently codified in a digitalized and globalized world characterized by harsh competition. Companies must have in-depth knowledge of communication patterns and tools, in order to achieve their purposes and maintain successful relationships with loyal customers. This study makes a qualitative analysis of communication patterns for companies from Belgium and Romania, active in a large area of diverse business fields. The data was collected through questionnaires and phone call conversations. The concept of communication was split into factors that were tested though 11 questions, referring to five work hypotheses: (1) direct communication is a top tool for companies; (2) customers' satisfaction is a top priority for companies; (3) customer loyalty is more important than customer acquisition; (4) national culture is not essential in the communication with customers; (5) companies prefer classic channels of communication over modern ones. The comparative analysis led to the confirmation or disproval of each of the afore-mentioned hypotheses. Furthermore, the influencing factors of communication are clarified through the outcome of the study. For a successful communication, companies need to analyse the given context under its most relevant aspects, be aware of the characteristics of the communication type used, take into consideration the relevant objective and subjective factors and build in meaning, joint purpose, learning potential and adaptability.
\end{abstract}

Keywords: relationship marketing; communication; comparative study; marketing study; qualitative research.

\section{Introduction}

Business communication driven by traditional, internal organizational values is less appealing to the selective, well informed, educated customer of our times. The dramatic influence of technology on business, the increased ethical awareness and the ease of social interaction between customers through electronic media are changing the face of business. Contemporary society has molded a new type of better informed customer who decides for a product or service based on personal values. Thrassou and Vrontis (2009, p. 514) call this new process of marketing communication a "symbiotic relationship" between customer and company.

This exploratory study contains a comparative analysis between the communication patterns used by companies active on the Romanian and Belgian markets. It takes into account the theoretical streams of marketing communications and relationship marketing and stretches into the international context of international relationship marketing.

\subsection{Literature review}

Marketing communications witnessed multiple changes under the push and pull effect of the internet and the development of IT technology. One of the main transformations is the switch from interpersonal relationships through face-to-face communications to IT based business interactions (Maxim, 2009). However, companies tend to over-rely on computers and virtual media as main channels of communication with customers and clients (Effiong, 2018). In this context, some organizations seem to have neglected the importance of problem solving and information gathering 
through personal contact with the customer (Lascu et al., 1993). The result is a communication style similar to a one-sided monologue, where the information and advertisements presented to the customer do not correspond to their needs and can have an adverse effect (Effiong, 2018).

Relationship communication was defined by Finne and Gronroos (2009) as "any type of marketing communication that influences the receiver's long term commitment to the sender by facilitating meaning creation through integration with the receiver's time and situational context" (p. 180). The time context refers to the receiver's perception of the past and future of their relationship with the sender.

Existing research shows that relationship communication is a benchmark for comparison and evaluation of service quality (Effiong, 2018). Moreover, communication effectiveness was identified as the most powerful criterion of relationship commitment in the service industry (Sharma \& Patterson, 2000; Aburoub et al., 2011). The link between value and loyalty has been confirmed and well established (Bıçakcıoğlu, 2018; Verma et al., 2016; Stancioiu \& al., 2013). Hänninen and Karjaluoto (2017) conducted a study, which inquired how communication quality and various marketing communication channels affect the transformation of customer-perceived value into customer loyalty. Interestingly, the use of different channels of communication and frequent communication was found to be perceived as more important than the quality of communication. It seems that communication frequency is a driver of communication quality (Hänninen \& Karjaluoto, 2017; Mohr \& Sohi, 1995). Personal communication via device, such as video negotiations and internet calls, followed by face-toface communication, were found to be the most effective in terms of communication.

Communication via device is easy and low cost to use and it enables transmission of non-verbal and para-verbal cues, without requiring physical proximity or travel arrangements (Hänninen \& Karjaluoto, 2017). The fact that this device-mediated communication can take place frequently is an important positive factor in fostering the relationship (Pop, 2018). E-mail interaction is also perceived as a personal communication channel, provided that the relationship is already well established (Hänninen \& Karjaluoto, 2017) (Hapenciuc et al., 2015). Surprisingly, the costly participation in fairs and shows was rated as much less effective by customers and mass media was also found not to have a statistically significant impact. The company website is a good must have factor, but it was not found to benefit an existing relationship. Moreover, mere presence on social media does not make for an effective communication either (Hänninen \& Karjaluoto, 2017). To the contrary, it seems that the potential of social media remains largely unused by business marketing (Hänninen \& Karjaluoto, 2017; Jussila et al., 2014). There is a gap between the perceived benefits and actual implementation of social media. The root cause might be the fact that modern, digital tools, such as websites and e-mail, are not a replacement for classic, offline tools, but rather an additional resource for attaining marketing and communication objectives (Cawsey \& Rowley, 2016; Karjaluoto et al., 2015). Therefore, the mere usage of social media does not transfer directly to relationship outcomes, unless it is embedded in a customer-centric communication strategy, which combines classic and modern capabilities (Trainor et al., 2014).

Relationship building is complex and depends on many factors that are hard to measure. Goodquality communication is characterized as sufficiently frequent, useful in terms of content, sent through suitable channels and perceived as efficient (Hänninen \& Karjaluoto, 2017). Finne and Gronroos (2009, p. 186) propose that "meaning creation" forms the core of relationship communication, while time and situation are key dimensions of meaning creation in relationships (Gronroos, 2000). The complexity of the communication process is presented as follows: "relationship communication differs from other forms of communication because of the relative meanings attached by the receiver of messages" (Effiong 2018, p. 252). Receivers interpret or perceive messages based 
on their mind-sets, on past experience and expectations, and this changes the meaning of the received message.

It is therefore essential to carefully identify and analyze the criteria, which could motivate the customer to interpret and ascribe positive meanings to messages received in a business relationship (Pop et al., 2012). This implies an analysis of the costs and benefits of adaptation or customization of messages rather than over-emphasizing generic messages, which may not accommodate the customers' needs.

Services and products have a symbolism that is affecting the way people relate to them (Hakkio \& Laaksonen, 1998). It can be a symbolic meaning of the product or a meaning that the consumer invests it with. The symbolic meaning is enforced by the marketer who acts as mediating filter between the nature that a product has and the role it plays for the consumer (Pelau \& Chinie, 2018). When products are fulfilling similar needs in alike ways, the symbolism is used as a differentiating factor.

The review system of services and products offers customers the possibility to express their opinion and provides them with the necessary information to take a decision, as the studies show that $84 \%$ of the people trust the online reviews (Schuckert et al., 2015). Word of mouth, and its electronic equivalent of online forums, proves to be a significant differentiating factor among similar brands (Shardanand \& Maes, 1995). However, if the communication flow is overwhelming or too dispersed, it risks producing an information overload and it has counter-productive effect on customers' willingness to receive marketing communication (Bright et al., 2015; Sasaki et al., 2015; Bawden and Robinson, 2009).

As markets become more dynamic and competitive, companies need to develop new coping strategies, in order to survive. Financial and price incentives are not sufficient in this context. Value driven meaning and relationship building are ways of coping constructively with present challenges. Upon reflection, this brings business back to values and relationships that were common in preindustrial revolution era, characterized by small-scale workshops, guilds, high quality products, high attention and time investment in products, as well as personalized relations with the buyers (Gârdan, 2011). This type of value and relationship driven business comes back nowadays in a globalized and highly technologized context.

Parasuraman, Zeithmal and Berry (1988) have determined that the following factors can influence customers' perception of service quality: (a) reliability - the ability to deliver promised qualitative services in terms of time, manner and cost; (b) responsiveness - readiness to respond to the customer as required; (c) empathy - the belief by the customer that the company understands their situation; and (d) assurance/physical evidence - tangible proof supplied to the customer with regard to specific service performance.

Moreover, there are particular attitudes that are prone to foster rich and fulfilling relationships: generosity, trust, commitment, joint purpose (Pop et.al., 2012; Veerasamay, 2011; Hess \& Sory, 2005; Delgado-Ballester \& Munuera-Alemán, 2001; Duncan \& Moriarty, 1998; Garbarino et al., 1994; Peck, 1993), as well as "truth, candor and straight talk mixed with compassion and care" (Veerasamay 2011, p. 2357).

In order to maintain customers' loyalty, companies have to invest in corporate image, as well as in relation building. Companies have increasingly started to aim for retaining clients and transforming them in partners by ensuring repeated acquisitions, rather than pursuing new customers (Kim \& Lee, 2010). A study on service quality and customer switching behavior in China's mobile service sector (Liang et al., 2012) has proven that the top factors that determine customers to switch service providers are core service failure, high price and ethical problems. The results are similar to the outcomes of studies performed in Western societies (Keaveney, 1995) and thus point to global 
prerogatives for service excellence. This consistent cross-cultural finding indicates that providing high quality product or service is the key to companies' success. In addition to that, we can see that in collectivistic societies (such as the Chinese one), the impact of family, friends or other close groups is more important than in individualistic societies, such as Western ones.

International Relationship Marketing studies have proven that service quality, satisfaction, quality of relationship and service design are positively correlated with customer retention and customer loyalty (Keaveney, 1995) (Baba \& Stancioiu, 2018). However, it should be noted that customers can switch providers even if they are satisfied, e.g. switching due to competition, family/friends/group impact and price, or may stay with a service firm, in spite of their dissatisfaction, due to high barriers such as the switching cost (Liang et al., 2012).

The study of the theoretic foundation of International Relationship Marketing shows that three periods can be distinguished in the research of this field (Samiee et al., 2015):

1) The origination period (1972-1993) focused on transaction costs analysis and on the evaluation of relationships between international firms and their operating environment.

2) The intermediate period (1994-2003) focused on the companies' resources, the entry mode on national markets, on joint ventures and on the role of commitment and trust in the marketing channel.

3) The late period (2004-2013) emphasized resource dependency and need to develop interpersonal relationships, as well as to increase knowledge and learning, which enable adaptability to change and competitive advantage.

The current exploratory study is not directly attributable to the International Relationship Marketing-research, however it relates to it by clarifying and comparing business communication patterns on different national markets.

\subsection{Hypotheses}

The literature review in the fields of relationship marketing, marketing communication and international relationship marketing leads us to the formulation of several hypotheses:

$\mathrm{H} 1$ - Direct communication with customers is among the top three most important tools to increase trust.

$\mathrm{H} 2$ - Customer's satisfaction is a top priority for companies and its measurement is more important than immediate profitability.

H3 - Communication is firstly aimed at cultivating customer loyalty and secondarily aimed at acquiring a new customer.

$\mathrm{H} 4$ - National culture does not play an essential role in communicating with customers. The essential role is played by emphasizing the inherent qualities of the product or service.

H5 - Companies prefer classic channels of communication with customers over modern ones. Modern channels of communication are underused.

\section{Method}

Communication efforts of companies operating in a ripe market were compared with those of companies operating in a relatively new capitalistic market, opened 30 years ago. The companies are both national and international and they activate in a diversity of fields, including house and personal care products, fashion, insurance, banking, IT development, travel, agriculture, zero waste sector, ecological products, event management, pharmaceuticals, food products etc. A set of questionnaires containing 11 questions, addressing the hypotheses above, were distributed to B2C and B2B companies in Romania and Belgium. The questionnaire structure was identical. The questionnaires distributed in Belgium were written in English, while the questionnaires distributed in Romania were translated in Romanian by mother tongue speakers, bearing in mind cultural and linguistic 
considerations. 11 out 22 contacted companies responded to the received questionnaire in Romania. 5 out of 22 contacted companies responded to the received questionnaire in Belgium. In order to incentivise the response rate, companies were proposed the option of receiving a research executive summary. Telephone contact was undertaken with 15 out of 22 contacted companies in Romania and 19 out of 22 contacted companies in a Belgium. The phone contact was a follow-up to the initial contact, aimed at (1) increasing the participation in the study and (2) adding an experimental recording of the quality of the interaction with the company's employees. The quality of interaction was rated by using a specially designed interaction review sheet containing yes/no binary questions and ranking on 1 to 10 Likert scale for indicators such as: a) amount of time to reach an employee, b) politeness, c) professionalism, d) concrete issue resolution, and e) general impression. The collected information fed further data into the qualitative assessment of the companies' communication styles and relationship building abilities.

\section{Results}

\section{The case of Belgium}

\section{H1 Direct Communication is a top tool for companies}

All the participating companies are maintaining forms of direct communication with their customers. Smaller companies tend to have an organic, instinctive approach to communication, preferring reliable contact, being transparent on the product details, emphasising the quality and preferring personal contact, albeit in written form. The larger a company is, the more they are inclined to sophisticated customer retention programmes such as fidelity bonus cards, personalised mailing lists and active Instagram and Facebook accounts. Direct communication can occur through conference video calls, social media messaging or answering written queries. Taking care of appointing the same person as contact point also contributes to trust and continuity in communication. Close contacts and sharing key values was highlighted as a priority. As these elements relate to direct communication, we can conclude that the first hypothesis is confirmed.

\section{H2 Customers' satisfaction is a top priority for companies}

All participating companies are preoccupied with customer's satisfaction. There is a high awareness that a satisfied customer generates turnover and profitability, becoming an ambassador of the business. Elements used to raise customer satisfaction are ethical attributes of the products or services, quality attributes, responsiveness to issues raised by customers, finding win-win solutions to problems. Smaller firms are particularly sensitive to ethical business models and they reach their customer through transparency, traceability, honesty and consistency. It is important that the customer is invited to be precise about their expectations and to meet those expectations with suitable personalised advice. A success factor of satisfaction is to involve the customer throughout a clearly defined process with transparent milestones. Satisfaction is explicitly monitored by larger firms through yearly satisfaction surveys and Net Promotor Score survey. Smaller firms measure satisfaction indirectly by means of indicators such as fidelity account subscriptions, reactions on social media accounts and customer's loyalty. We therefore conclude that the second hypothesis is confirmed.

\section{H3 Customer loyalty is more important than customer acquisition}

Smaller companies tend to prefer customer acquisition and have at least a 50/50 per cent resource input in both acquisition and retention of customers. However, large companies tend to prefer retaining their customers, as both parties know each other's deliverables, values and expectations. Negotiation of terms of service as such is extremely rare. There are cases of giving rebates and vouchers in order to compensate for a problem, however, a genuine before-hand negotiation of conditions was not reported. A deeper inquiry into industrial production relationships might highlight that this practice is practiced especially in such specific contexts. When it comes to demonstrating the 
benefits of own products and services, companies employ a variety of tools such as website information, oral presentations, technical documentation, visible product attributes or symbolic, status driven reinforcement, such as brand image. It is interesting to note that most companies employ emotional cues, even in cases of pure technical matters. We can conclude that marketing communication is particularly aimed at acquiring new customers and that the relationship aspect of customer retention emerges with larger companies where survival of the business is not an issue anymore. We conclude that the third hypothesis is confirmed for larger companies, which aim primarily for customer retention and loyalty. The hypothesis is disproved for smaller companies, which tend to aim primarily for customer acquisition.

H4 National culture is not essential in the communication with customers

All participants gave overwhelming evidence of the high importance of cultural aspects at national and local level. In some cases, the business model is based entirely on harnessing the national or local advantages in the framework of international partnerships. Exigent customers demand specific origin of products for reasons ranging from environmental, ethical and status driven. In certain cases, the entire business model is centred around the origin of products. The case of Belgium is particular because of the language and identity divide between Wallonia and Flanders, as well as the presence of large international supra-governmental institutions, such as the EU and NATO, which draws in a high number of foreign population. Companies tend to consider the diversity of culture as an opportunity. The phone inquiries also highlighted differences in client request treatment and interaction in communication, with Flanders getting the upper hand in concrete case resolution and overall communication performance. We can conclude that the fourth hypothesis is disproved, as national and local culture are essential.

\section{H5 Companies prefer classic channels of communication over modern ones}

Modern, electronic communication prevails for all responding companies, with the lowest percentage of electronic media use being $65 \%$ and the highest being $100 \%$. As a matter of consequence, most companies indicated that the Internet and social media brought them a high business advantage, facilitating contact with customers by tapping into a reservoir of accessible and free tools. We can conclude that the fifth hypothesis is disproved, in the sense that a mix of both communication types is generally used.

\section{The case of Romania}

\section{H1 Direct Communication is a top tool for companies}

The start-ups and the small companies in Romania consider direct communication as the most effective way to form partnerships, to attract clients and to develop. Therefore, they constantly and openly communicate to all stakeholders. The first contact person in charge with communication is often the communication manager, instead of a specialized employee. This is meant to convince and address situations with a bigger picture perspective. The big companies, which are covering a bigger market share, don't directly communicate with the client, but they appeal to specialized companies to monitor the market and the consumer opinions. The closest interaction of direct communication is through advertisement campaigns, or during business meetings with partners. We can conclude that the first hypothesis is confirmed for small companies and disproved for larger companies.

\section{H2 Customers' satisfaction is a top priority for companies}

Customer satisfaction is extremely important both for the small companies, who need to grow and need positive reviews, as well as for the big companies, who need to protect the market image they have consolidated and try to address problems. The methods used to ensure that, include the followup through phone or email after a purchase or use of service, a reward system for loyal customers and a compensation mechanism for unsatisfied customers in case of reclamations, as well as free products 
and services or vouchers to bind the customers to the company. We conclude that the second hypothesis is confirmed.

\section{H3 Customer loyalty is more important than customer acquisition}

Both attracting new clients and keeping the existing ones is highly important for the success of a company. Most of the companies interviewed in Romania are having direct contact with the clients and they do negotiate contracts. The unanimously adopted strategy was a win-win situation between the clients and the company. Some companies practice very low prices, however communication is very important in this case as well, in order to transmit the right message. Others resort to actions aimed at consolidating the market image. All the companies that answered the questions admitted that they are investing equally in the existing clients and in attracting new ones, the percentage being slightly over $50 \%$ for strategies to retain customers. Existing customers have the potential to grow and to attract new customers through word of mouth, which is a proven powerful marketing tool. Only the companies that are new on the market admitted to be more involved in attracting new clients due to their need to evolve, but they do not seem to neglect the relationship building aspect. We conclude that the third hypothesis is confirmed for larger companies and to a lesser extent for smaller companies, which seem to focus slightly more on customer acquisition.

\section{H4 National culture is not essential in the communication with customers}

National culture is very important for companies that act on service markets. Understanding the client and offering services that are adapted to their needs and cultural differences can assure a longterm relationship. For service companies that offer expensive products, which are less known in Romania, the company has to make additional efforts to reduce the national difference between the country of origin and the consumption market, this being possible through information sessions, workshops and convincing proofs. National stereotypes and believes that customers might have are taken into consideration in the communication strategies. International companies that act on a local level employ local people, in order to bridge cultural differences and reduce the communication barriers. The Romanian companies that work for foreign customers are transparent about the origin of their work and they reported to use the cultural difference as a marketing tool, in order to raise the attractiveness of their offer. We can conclude that the fourth hypothesis is declined, as a cultural based communication is more than a marketing tool, it is essential in the relationship building and in shaping the offered service or product.

\section{H5 Companies prefer classic channels of communication over modern ones}

Both traditional and modern means of communication have their advantages and disadvantages. The best option for each business seems to be a blend of the two, according to the field of activity. The classical business fields that have been existing for a long time on the market, and whose value-added for the customer are of personal nature, such as medical services, assurance, law firms, taxation, banking etc., benefit of more success when the communication is done in a classic way. The most powerful tool they use is the word of mouth, as trust building is essential in those fields, and binding the customer on the long run is the most common strategy. Even if the business is done mostly offline, and the face-to-face communication has utterly more effect that any other modern way, they still adapt constantly to the new media, as they have to cover different areas of customers. Moreover, the traditional means of communication are proven to be very strong and significant in any business. However, the modern communication methods are gaining in power and the technology development is defining the future business model. Therefore, it is not enough for a company of any kind to invest in the traditional communication methods, but they should be covered both online and offline, in order to survive in the business. For these reasons, those companies are investing in social media, Linkedln, YouTube and Adwards, as they consider that it brings notoriety and visibility. For the businesses that are more oriented on creativity and innovation, the new communication areas are essential. Some businesses are created exclusively on electronic basis and they keep the pace with innovation. 
Nevertheless, even the companies that work exclusively online, have admitted that the classic communication, including the face-to-face meetings, is the most effective. According to them, almost every personal contact has ended in a contract, more than any other online binding strategy. In conclusion, classic communication and modern communication channels do not exclude each other. Each company has to choose the percentage of online and offline communication they use. While the IT and tech companies extended the online communication to more than $90 \%$, some banks and insurance companies keep the offline communication in more than $80 \%$ of the cases.

\section{Discussion}

The same set of questions was addressed to both Belgian and Romanian companies. Similarities and discrepancies between the two markets emerged. Both in Belgium, as in Romania, the direct communication is rather specific for smaller companies, who need constant feedback for their activity. This is less the case for large companies who appeal to external services for market research or which employ annual questionnaires. Customer satisfaction was mentioned as a key priority for both small and large companies active in both markets. Another common point for both markets is the perception regarding the retention or acquisition of customers. In the first stages of the business it is more important to invest in attracting more stakeholders, while, in later stages, the retention of the customers is cheaper and more reliable, therefore customer retention is preferable. Both countries are characterized through the Hofstede model (Hofstede, 2011) (Pelau \& Pop, 2018) as largely avoiding uncertainty, though, in some cases, slightly more companies are akin to pursue new customers in Romania than in Belgium. In Belgium, the national culture represents a key element of the product/service design, while in Romania companies tend not to prioritize the national cultural specification. The cultural differences are still very obvious, despite the globalization trend. In Romania companies often adopt international trends, without making significant adjustment, as most customers desire to align to the global trends. Therefore, companies tend to let the customer adopt the product, rather than adjusting it to local culture. When it comes to technology, both countries are very much developed, and they turned a big part of the business online. However, while participating companies from Belgium moved more than $65 \%$ of the communication online, the one from Romania stick more to the face-to-face communication. The reason for that is the reluctance of some customer segments to use online credit card online, the customer's necessity to check the product and to have human interaction when choosing a product.

We also observe a tendency of large companies from the ripe Belgian market to be less open towards participation in surveys. Their market share is guaranteed, and they reported over the phone to be flooded with surveys. This indicates a certain inward-looking tendency, which seems more typical of big structures or of small and overloaded entities. The phone call conversations reflected a high level of preparation of employees in terms of active listening and professional dialogue. However, employees often express their lack of authority for providing a specific contact point or they avoid scaling up the request, preferring to postpone the resolution of the problem. Although the ratings of the conversations are high, only one company was in the position to receive the maximum score due to concrete problem resolution. Smaller companies are more reachable and open to flexible solutions. Companies in Romania were more likely to consider the comparative research as an opportunity to learn and develop. This might indicate a correlation between the development stage of the market, the size of the company and their openness to interact with the broader environment, beyond shareholders and customers. 
Comparing the Romanian and Belgian market experiences and analysing the communication process of the companies participating in this study, one can see in Figure 1 the process for an effective communication of companies with their customers. The figure is based on the research results of the authors, supported by the consulted literature.

Figure 1: How to communicate effectively with customers?

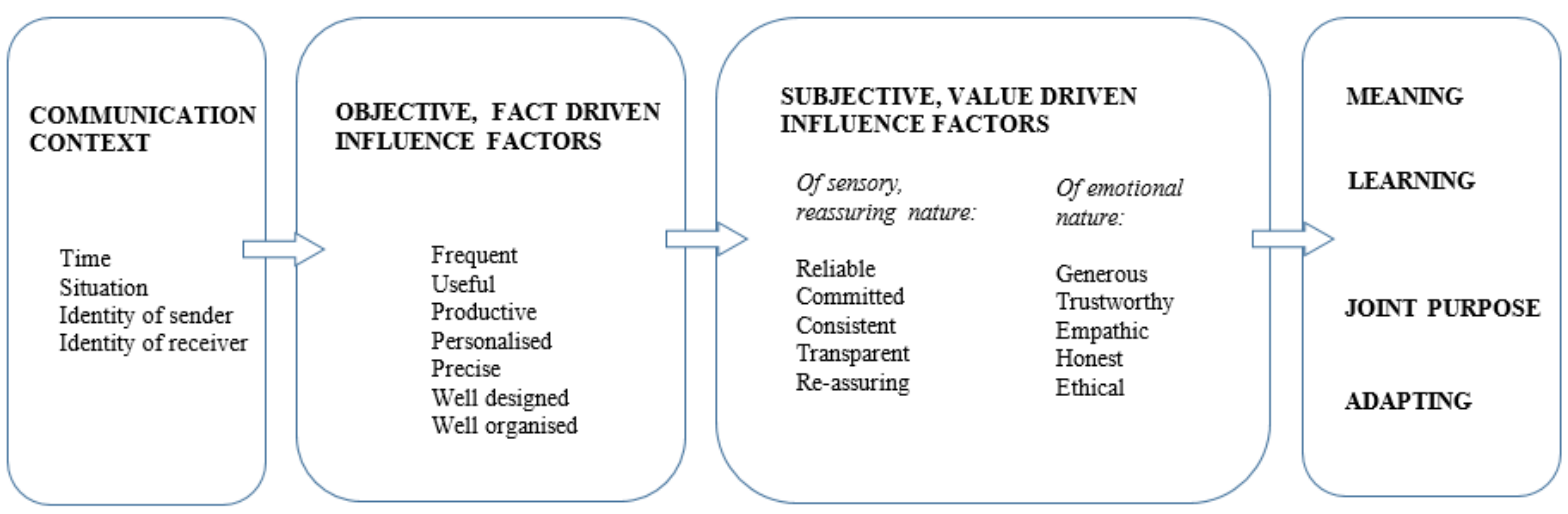

\section{Conclusion}

Direct communication is as fashionable as ever, both in face-to-face and in electronic forms. For a successful communication, companies need to analyse their operating context under its most relevant aspects, namely the time, situation and identity of receiver. Communication ambassadors (albeit sales people, managers, marketing employees, or any other employee with representative and communication attributions) need to know the company's own values and identity features. Furthermore, the communicating company must be aware of the characteristics of the channel of communication that is being used (face-to-face communication, electronic communication, personal communication via device, written communication via messaging, e-mail or letter). Communication is influenced by a series of both subjective, value driven factors, and objective, fact driven factors, which need to be acknowledged and respected. At last, the communication process is successful only when there is finality, namely, where the message has managed to convince and influence. For medium and long-term perspectives, this finality is not (only) purchasing the product or the service, but creating meaning, joint purpose, learning and adapting.

\section{References}

[1] Aburoub, A. S., Hersh, A. M. and Aladwan, K. (2011). Relationship between internal marketing and service quality with customer satisfaction. International Journal of Marketing Studies, v. 3, n. 2, p. 107-118.

[2] Baba, C.-A. and Stancioiu, A.-F. (2018). Considerations regarding applicable Marketing Strategies in the Adventure Tourism, from a youth perspective. International Conference on Marketing Business Development, Bucharest, Romania, 1(2), pp. 77-83.

[3] Bawden, D. and Robinson, L. (2009). "The dark side of information: overload, anxiety and other paradoxes and pathologies", Journal of Information Science, vol. 35 No. 2, pp. 180-191.

[4] Beard, F. (1996). Integrated Marketing Communications: New Role Expectations and Performance Issues in the Client-Ad Agency Relationship?, Journal of BusinessResearch, J37, pp. 207-215.

[5] Bıçakcıoğlu, Nilay, İpek ỉlayda \& Bayraktaroğlu Gül (2018) Antecedents and outcomes of brand love: the mediating role of brand loyalty, Journal of Marketing, pp 863-877. 
[6] Bright, L.F.; Kleiser, S.B. and Grau, S.L. (2015). "Too much Facebook? An exploratory examination of social media fatigue", Computers in Human Behavior, vol. 44, March, pp. 148-155.

[7] Delgado-Ballester, E., and J. L. Munuera-Alemán (2001). "Brand Trust in the Context of Consumer Loyalty." European Journal of Marketing 35 (11/12): 1238-1258.

[8] Duncan, T., and Moriarty, S. E. (1998). "A Communication-based Marketing Model for Managing Relationships." Journal of Marketing 62: 1-13.

[9] Finne, A. and Gronroos, C. (2009). Rethinking marketing communication: From integrated marketing communication to relationship communication. Journal of Marketing Communications, v. 15, n. 2-3, p. 179-195.

[10] Garbarino, E., and Johnson, M. S. (1999). "The Different Roles of Satisfaction, Trust, and Commitment in Customer Relationships." Journal of Marketing 63 (2): 70-87.

[11] Gârdan, D. A. (2011). New Perspectives in Relationship Marketing Conceptualization. Annals of Spiru Haret University, Economic Series, Universitatea Spiru Haret, 2 (4), pp. 81-89.

[12] Gronroos, C. (2000). Service management and marketing: A customer relationship approach, London: John Wiley \& Co.

[13] Hakkio, S. and Laaksonen, P. (1998). Relationships in Marketing Channels: Examining Communication Abilities through Cognitive Structures. Psychology \& Marketing, 15(3), 215-240.

[14] Hänninen, N. and Karjaluoto, H. (2017). "The effect of marketing communication on business relationship loyalty", Marketing Intelligence \& Planning, Vol. 35, Issue: 4, pp.458-472.

[15] Hapenciuc, C. V., Pînzaru, F., Vatamanescu, E.-M. and Stanciu, P. (2015). Converging Sustainable Entrepreneurship and the Contemporary Marketing Practices. An Insight into Romanian StartUps. Amfiteatru Economic, 17(40), pp. 938-938.

[16] Hess, J., and J. Story. 2005. "Trust-based Commitment: Multidimensional Consumer-brand Relationships." Journal of Consumer Marketing 22 (6): 313-322.

[17] Hofstede, G. (2011). Dimensionalizing Cultures: The Hofstede Model in Context. Online Readings in Psychology and Culture, 2(1).

[18] Jussila, J.J., Kärkkäinen, H. and Aramo-Immonen, H. (2014). "Social media utilization in businessto-business relationships of technology industry firms", Computers in Human Behavior, Vol. 30, pp. 606-613.

[19] Keaveney, S. M. (1995). Customer switching behavior in service industries: An explorative study. Journal of Marketing, 59(2), 71-82.

[20] Kim, Y.-E. and Lee, J.-W. (2010). Relationship between corporate image and customer loyalty in mobile communications service markets. Africa Journal of Business Management, 4(18), 40354041.

[21] Lascu, D., Manrai, L. A. and Manrai, A. K. (1993). Marketing in Romania: The Challenges of the Transition from a Centrally-planned Economy to a Consumer-oriented Economy. Marketing in Romania: The Challenges of the Transition from a Centrally-planned Economy to a Consumeroriented Economy", European Journal of Marketing, 27(11), pp. 102-120.

[22] Liang, D., Zhenzhong, M. and Liyun Q. (2013). Service quality and customer switching behavior in China's mobile phone service sector. Journal of Business Research, Vol 66, pp. 1161-1167.

[23] Maxim, A. (2009). Relationship marketing - a new paradigm in marketing theory and practice. Analele Stiintifice ale Universitatii "Alexandru Ioan Cuza" din lasi - Stiinte Economice.

[24] Mohr, J.J. and Sohi, R.S. (1995). "Communication flows in distribution channels: Impact on assessments of communication quality and satisfaction", Journal of Retailing, Vol. 71 No. 4, pp. 393-415.

[25] Parasuraman, A.; Zeithaml, V. A. and Berry, L. L. (1998) Servqual: A multiple-item scale for measuring consumer perception of service quality, Journal of Retailing, v. 64, n. 1, p. 12. 
[26] Peck, H. (1993). Building Customer Relationships through Internal Marketing: A State of the Art Review, Emerging Issues in Marketing, Proceedings of the 1993 Annual Conference of the Marketing Education Group, Loughborough University, Loughborough, UK, 797-813.

[27] Pelau, C. and Chinie, A., 2018. Clusters of Tourism Consumers in Romania. Studia Universitatis "Vasile Goldis" Arad - Economics Series, 28(1), p. 17-34.

[28] Pelau, C. and Pop, N.A. (2018). Implications for the energy policy derived from the relation between the cultural dimensions of Hofstede's model and the consumption of renewable energies. Energy Policy, Volume 118, pp. 160-168.

[29] Pop, N. A. and Baba C. A. (2018). Factors influencing adventure tourism in Romania in a sustainable perspective. New Trends is Sustainable Business and Consumption, Heidelberg, Germany.

[30] Pop, N. A., Roman, M., Săniuță, A. and Petrișoaia, C. (2012). Relationship Marketing, Engine of sustainable Development and Organizational Change in the Romanian Business Environment. Amfiteatrul Economic, XIV(32), pp. 348-363.

[31] Sasaki, Y., Kawai, D. and Kitamura, S. (2015), "The anatomy of tweet overload: how number of tweets received, number of friends, and egocentric network density affect perceived information overload", Telematics and Informatics, Vol. 32 No. 4, pp. 853-861.

[32] Schuckert, M., Liu, X., and Law, R. (2015). Hospitality and Tourism Online Reviews: Recent Trends and Future Directions. Journal of Travel \& Tourism Marketing, 32(5), 608-621.

[33] Shardanand, U., and Maes, P. (1995). Social Information Filtering: Algorithms for Automating "Word of Mouth" Social information filtering. Proceedings of the SIGCHI Conference on Human Factors in Computing Systems - CHI '95. Denver, Colorado

[34] Sharma, N.; Patterson, P. G. (2000). Switching costs, alternative attractiveness and experience as moderators of relationship commitment in professional consumer services, International Journal of Service Industry Management, v. 11, n. 5, p. 470-490.

[35] Stancioiu, Aurelia-Felicia; Botos, A.; Orzan, Mihai; Pirgaru,lon; Arsene, Octavian (2013). Comunicare integrata de marketing în turism - o analiză. Studiu de caz: Mantenía și Oltenia. Economie teoretică şi aplicată, XX (6), pp. 4-30.

[36] Thrassou, A. and Vrontis, D. (2009). A new customer relationship Model: The marketing communication Application. Journal of Promotion Management, n. 15, p. 499-521.

[37] Trainor, K.J., Andzulis, J.M., Rapp, A. and Agnihotri, R. (2014), "Social media technology usage and customer relationship performance: a capabilities-based examination of social CRM", Journal of Business Research, Vol. 67 No. 6, pp. 1201-1208.

[38] Veerasamy, D., (2011) The role of communication in promoting relationship marketing within the cellular industry in South Africa, African Journal of Business Management, Vol. 5(6), pp. 2356-2362.

[39] Verma, V., Sharma, D.; Sheth, J. (2016). Does relationship marketing matter in online retailing? A meta-analytic approach. Journal of the Academy of Marketing Science, Vol. 44(2), pp. 206-217.

[40] Wuthnow, R., Hunter, J. D., Bergesen, A., \& Kurzweil, E. (1984). Cultural analysis. The work of Peter L. Berger, Mary Douglas, Michel Foucault and Jurgen Habermas. Boston: Routledge \& Kegan Paul. 